\title{
Plastic Composites Made from Glycerol, Citric Acid, and Forest Components
}

\author{
Rasika L. Kudahettige-Nilsson, Henrik Ullsten, and Gunnar Henriksson * \\ An ecofriendly approach for the synthesis of plastic biomaterials based on \\ renewable materials suitable for 3D printing application or other \\ applications has been developed. The material was prepared from native \\ (microcrystalline) or amorphous cellulose, citric acid, and glycerol or \\ ethylene glycol, by a pretreatment at $40^{\circ} \mathrm{C}$ and a curing at $175^{\circ} \mathrm{C}$ for $1 \mathrm{~h}$. \\ The results showed that tensile properties and the water absorption level \\ of the material were acceptable. The highest strain at break (14\%) was \\ obtained from materials made of $10 \%$ amorphous cellulose with $90 \%$ \\ glycerol/citric acid. It had a maximum stress at $37 \mathrm{MPa}$. Moreover, \\ materials were without ash content. Possible applications of the material \\ in 3D-printers were discussed. In addition, application of mechanical pulp \\ and wood powder into novel plastic material production was discussed. \\ Foaming during curing might be a problem for this type of material, but this \\ can be avoided by using amorphous cellulose in the recipe.
}

Keywords: Amorphous cellulose; Microcrystalline cellulose; 3D printing; Plasticizer; Citric acid; Glycerol; Tensile properties

Contact information: Department of Engineering and Chemical Sciences, Karlstad University, SE-651 88 Karlstad, Sweden; *Corresponding author: ghenrik@kth.se

\section{INTRODUCTION}

In manufacturing permanent and disposable items for everyday use, plasticity is a very important factor for construction. Plastic materials can be formed easily into different shapes. The oldest type of material used by man for this purpose is ceramic material, which has been used and further improved since the Stone Age. Although ceramics are still important, they have drawbacks, especially for disposable items (food packages, etc.), in that they cannot be burned and are relatively heavy, which are properties that they share with metals. Plastic materials are widely used in world consumption (packaging, buildings, automobiles, household items, and toys), and most plastics used today are polymer-based materials characterized by plasticity (Wu et al. 2017).

In light of the mentioned advantages, it is not surprising that petroleum-based polymeric material such as polyvinyl chloride and polyethylene have been very successful in the last few decades. They can easily be formed into all kinds of shapes, are elastic, durable, and can be burned. However, over time, the drawbacks of an extensive use of petroleum-based plastic on large scale have become obvious. The raw material is nonrenewable, and both manufacturing and waste burning of plastic contribute to climate change. The most significant problem is uncontrolled disposal of plastic waste, which is ending up in oceans in huge amounts every day (Luyt 2017). Moreover, plastic waste in nature and in water is a growing environmental problem, since they are not biodegradable, and can cause severe problems for different life forms (Luyt 2017) by acting as organic toxic compounds and being mistaken for food by sea-living animals, which can block food 
digestion systems. Thus, it is of central importance that plastic materials made of renewable resources can be developed and come into large scale use (Wang et al. 2016). One increasingly popular application of plastics is $3 \mathrm{D}$ printing, which has been used to produce prototypes and molds for many years. It has increasing interest at present due to its wide range of potential applications (bio medical, industrial, and building construction) for consumer products (small accessories to large architectural structures) (Li et al. 2016). Carbon materials, due to their good chemical stability and versatile nanostructures, have been widely used in 3D printing. Carbon-based inks are mainly prepared in volatile solutions having carbon materials as fillers such as graphene oxide (GO), carbon nanotubes (CNT), carbon blacks and solvent, polymers, and other additives (Fu et al. 2017).

Materials based on lignocellulose are generally renewable and biodegradable and are thus attractive alternatives to petroleum-based plastic. One alternative is to convert cellulose into a plastic cellulose derivative, such as cellulose acetate, but the excessive cost is a problem. Products based on conventional pulp fibers are much cheaper, but the possibilities for forming materials are more limited, although products such as medium density fiberboards and egg boxes are examples.

Citric acid and glycerol are plasticizers and are used to increase the fluidity and flexibility of the material (e.g., plastics, concrete, wallboard, and clay) to which they are added (Tisserat $e t$ al. 2012). Moreover, citric acid is a potential crosslinking agent under acidic conditions that is rather inexpensive and nontoxic and has been used to improve the performance properties of cellulose and proteins in textile application (Reddy and Yang 2010; Yang et al. 1997; Menzel et al. 2013; Gonzáles Seligra et al. 2016). It is in most commonly produced organic chemicals via fermentation, and it is a natural component of a variety of vegetables and fruits. Moreover, it is a nontoxic metabolic product of the body (Krebs or citric acid cycle) and has already been approved by the FDA for its use with humans (Yang et al. 2004; Shi et al. 2007; Javed et al. 2016). The production of biodiesel via transesterification of vegetable oil or animal fat feed stocks has resulted in an enormous excess of glycerol as a co-product (Tisserat et al. 2012). Many plasticizers such as citric acid, glycerol, polyethylene glycol, sorbitol, xylitol, maltitol, and urea have been used as coating agents by blending with starch and polysaccharides (Lourdin et al. 1997; Garcia et al. 1998; Mathew and Dufresne 2002; Javed et al. 2016).

Catalyst-free thermal poly-esterification has recently emerged as a potential strategy for designing biodegradable thermoset polymers, particularly polyol based polyesters, which are synthesized through the polycondensation of polyol and polyacids without the presence of catalyst or solvents (Tham et al. 2016). The study of the synthesis of co-polyester from citric acid and glycerol has been demonstrated (Pramanick and Ray 1988). In this paper, a novel cellulose-based material was developed based on the crosslinking of cellulose molecules with glycerol/citric acid polyester without chemical catalyst or solvents (Fig. 1). Citric acid dissolved in glycerol, through a self-catalyzed condensation reaction, forms a polymer upon preheating at $40{ }^{\circ} \mathrm{C}$ until reaching a constant weight and curing at $175^{\circ} \mathrm{C}$ for 1 hour (Fig. 1). The curing reaction is a condensation reaction driven by the removal of water and might therefore occur at temperatures over 100 ${ }^{\circ} \mathrm{C}$. The reaction goes faster with higher temperature (unpublished data). As explained by Tham et al. (2016), thermostat polyesters can be synthesized by heating the monomers (polyol and polyacid) in a normal atmosphere or partial vacuum, followed by a post-curing procedure. This polymer can be, in principle, inserted into all components carrying alcohols during polymerization. Because wood polymers such as cellulose, hemicellulose, and lignin are rich in alcohols, this system becomes suitable for covalently crosslinking the 
components. The concept is attractive because both glycerol and citric acid are renewable and relatively inexpensive chemicals (Tisserat et al. 2012). A problem that remains is foaming due to water formation during curing.

This work examined a material based on cellulose and lignocellulose, mainly glycerol and citric acid, where glycerol and citric acid covalently crosslink lignocellulose polymers, and the glycerol works as plasticizer/medium. The material behaved like a thermoset gel, where objects can be formed to any shape, and heat treatment cured it to a hard material. Materials were prepared with different combinations of amorphous cellulose (6\% and $10 \%)$ and microcrystalline cellulose (20\% and $25 \%)$ with glycerol/citric acid (GC) and ethylene glycol/citric acid (EGC), respectively. In addition, the physical properties of heat treated hard materials such as tensile test, water absorption (WA), and ash content were determined. The conversion of lignocellulose biomass into new biomaterial by using plasticizers was demonstrated.
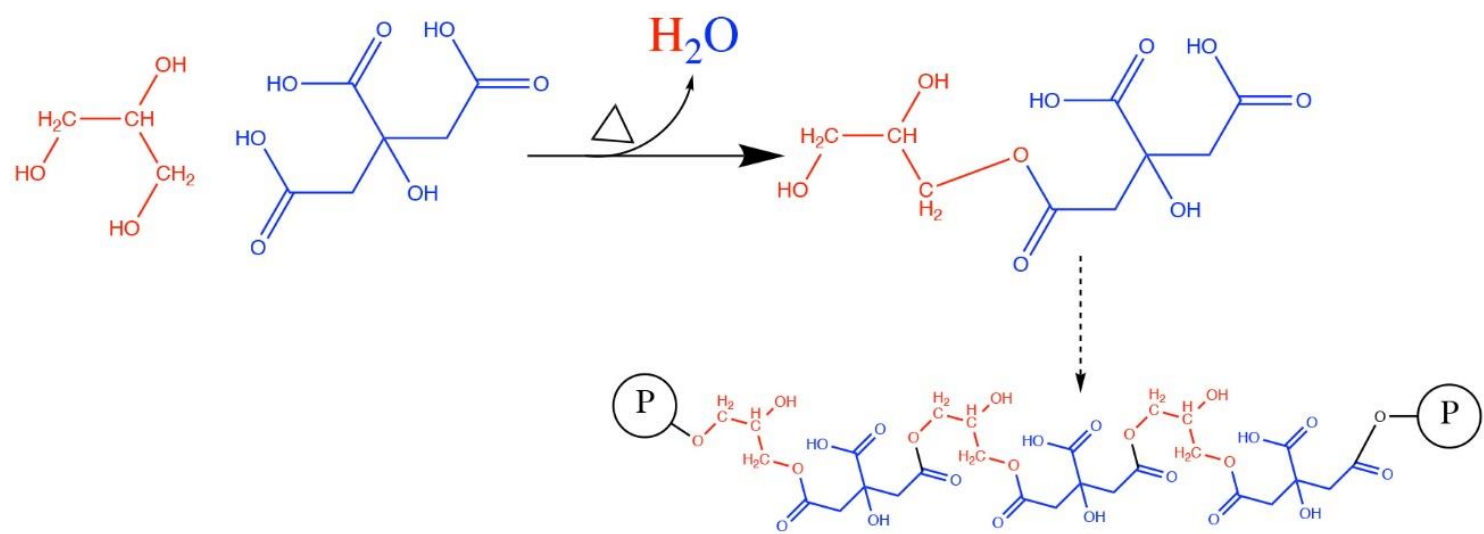

Fig. 1. The polymerization reaction of citric acid with glycerol. $P$ is natural polymer (cellulose/lignocellulose). The condensation reaction forms water, and when the temperature is above $100{ }^{\circ} \mathrm{C}$, the water is removed as steam, thereby stimulating the polymerization. The polymerization occurs at temperature over $100{ }^{\circ} \mathrm{C}$, but it is faster at higher temperature. At moderate temperatures over $100^{\circ} \mathrm{C}$, the curing can take several hours (over-night), whereas at temperatures around 175 to $200^{\circ} \mathrm{C}$ the curing might be ready within 30 mins to $1 \mathrm{~h}$.

\section{EXPERIMENTAL}

\section{Materials}

Avicel PH101 microcrystalline cellulose (crystal native), citric acid, glycerol, and ethylene glycol were purchased from Sigma-Aldrich, Stockholm, Sweden. Pulp fibers, specifically thermomechanical pulp (TMP), were bleached and of commercial grade made of Norway spruce (Picea abies) at Stora Enso mill, Kvarnsveden, Sweden. Wood powder was from The Wood Region, Torsby, Sweden.

\section{Methods}

Preparation of amorphous cellulose

Amorphous cellulose was prepared by dissolving Avicel microcrystalline cellulose (MCC) $20 \mathrm{~g}$ in $\mathrm{NaOH}(100 \mathrm{~g} / \mathrm{L})$ solution under magnetic stirring overnight at $4{ }^{\circ} \mathrm{C}$. 
The $\mathrm{pH}$ of the dissolved MCC mixture was adjusted to 10 using glacial acetic acid, which precipitated the cellulose in an amorphous swollen form. Amorphous cellulose was collected from the vacuum filter of the above mixture. The dry weight (DW) content of amorphous cellulose was determined at $105^{\circ} \mathrm{C}$ in an oven during overnight drying (Wang et al. 2014).

\section{Preparation of plasticizer mixtures}

Equimolar plasticizer mixtures (glycerol/citric acid) and (ethylene glycol/citric acid) were prepared at $40{ }^{\circ} \mathrm{C}$ mixing $600 \mathrm{rpm}$. To facilitate dissolving of the mixture, approximately $15 \%$ of deionized water was added.

\section{Plastic gel (cellulose based new biomaterial) preparation}

Different ratios DW (6\% and 10\%) of amorphous cellulose or DW (20\% and 25\%) of MCC were mixed with both above plasticizer mixtures according to Table 1, making a total DW of $5 \mathrm{~g}$. All mixtures were kept at $40{ }^{\circ} \mathrm{C}$ until constant DW was achieved. This material was called plastic gel (Fig. 2). After making different 3D printing forms of this material, curing was done at $175^{\circ} \mathrm{C}$ for $1 \mathrm{~h}$.

\section{Tensile properties}

The plastic gel sample chips (Fig. 3) of the above mentioned cellulose plasticizer mixtures were tested in a standard tensile tester Zwick/Roell Z005 (Ulm, Germany). The samples (chips) were 80 (height) $\times 7$ (width) $\times 2$ (thick) $\mathrm{mm}$, the initial grip separation was $20 \mathrm{~mm}$, and the cross-head speed was $10 \mathrm{~mm} / \mathrm{min}$. A total of 16 samples of each material were tested.

\section{FTIR (Fourier transform infrared spectroscopy) analysis}

FTIR spectra were obtained using an Agilent Cary 630 FTIR spectrophotometer (USA) equipped with a diamond attenuated total reflection (ATR) module. Spectra were processed using the MicroLab PC and Resolutions Pro software. The sample chips of plastic gel made of (25\% MCC $+75 \% \mathrm{GC}$ and $25 \% \mathrm{MCC}+75 \% \mathrm{EGC})$ before curing (40 $\left.{ }^{\circ} \mathrm{C}\right)$ and cured $\left(175^{\circ} \mathrm{C}\right)$ were analyzed at wavenumbers ranging from 650 to $4000 \mathrm{~cm}^{-1}$ at room temperature.

\section{Ash content (wet basis)}

Mixtures of amorphous cellulose and MCC with both above plasticizer mixtures [(1 g sample, wet weight $\left.\left(W_{\mathrm{WET}}\right)\right]$ were heated (muffle furnace) at $550{ }^{\circ} \mathrm{C}$ during $24 \mathrm{~h}$. After $24 \mathrm{~h}$, ash weight $\left(W_{\mathrm{ASH}}\right)$ was taken. Ash content (wet basis) was calculated according to, ash content (wet basis) $\%=\left(W_{\mathrm{ASH}} / W_{\mathrm{WET}}\right) * 100$.

\section{Water absorption capacity (WA)}

Plastic gel samples were immersed in $100 \mathrm{~mL}$ distilled water for $24 \mathrm{~h}$ (Altuntas et al. 2017). The sample weights before $\left(m_{0}\right)$ and after $24 \mathrm{~h}(m)$ of immersion were recorded. Water absorption capacity (WA) was determined as follows,

$$
\mathrm{WA}(\%)=\left[\left(m-m_{\mathrm{o}}\right) / m_{\mathrm{o}}\right] \times 100
$$




\section{RESULTS AND DISCUSSION}

A plastic material based on biomass (either microcrystalline cellulose or amorphous cellulose), glycerol/ethylene glycol, and citric acid was generated as described in Fig. 2. The original mixtures contained some water, and this was removed by drying at $40{ }^{\circ} \mathrm{C}$. The resulting material, a highly viscosity gel, was stable for months at room temperature (data not shown). The plasticity of the gel was demonstrated by pressing though a syringe, and the pattern produced was stable (Fig. 2). After forming the material into a desirable shape, it was cured in an oven at $175^{\circ} \mathrm{C}$ for $1 \mathrm{~h}$. After the heat treatment, the material was hard (Figs. 2 and 3e) and had often developed a light-yellow color (Figs. 2 and 3).

This hardening of the material could also be done by treating the sample in a microwave oven, or by exposure to hot oil (not shown) in similarity with the results by Tisserat et al. (2012). According to previous findings (Holser 2008), the second endotherm of differential scanning calorimetry (DSC) analysis of the material, equimolar glycerol/citric acid with $10 \mathrm{wt} \%$ starch indicated a peak at $182.5{ }^{\circ} \mathrm{C}$, including both reversible and nonreversible components. Moreover, the reversible component was attributed to the cornstarch, which displayed a broad melting endotherm over the temperature range of 160 to $220{ }^{\circ} \mathrm{C}$ (Holser 2008). Therefore, $175{ }^{\circ} \mathrm{C}$ was chosen as the hardening temperature, and the duration of curing was selected as $1 \mathrm{~h}$.

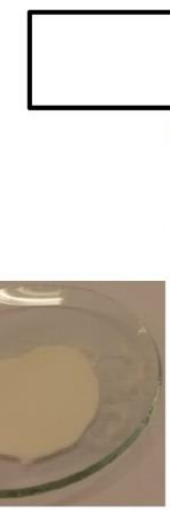

MCC

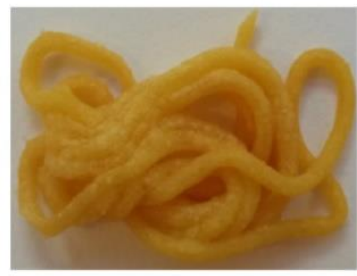

"Plastic gel" after curing
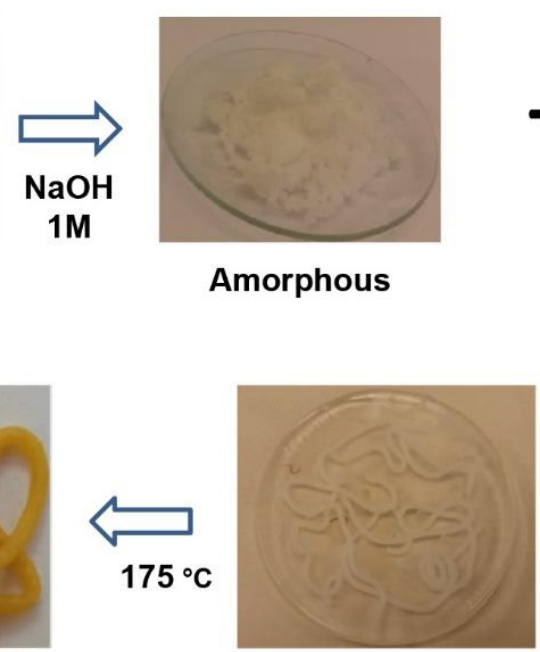

"Plastic gel" before curing

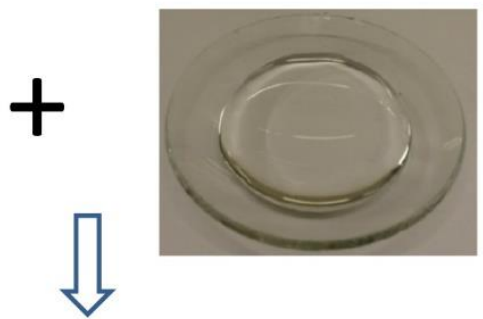

Fig. 2. The preparation of "plastic gel" using cellulose and plasticizer mixes (glycerol/ citric acid) and (ethylene glycol/citric acid)

A problem with the concept was that water vapor was formed by the condensation reaction of glycerol/citric acid during the heat treatment (Fig. 1) and ethylene glycol/citric acid, which caused the material to foam (Figs. 3a and 3b). One solution was a heat 
treatment at a lower temperature, but this would lead to unacceptably long curing times. This study found intensive foaming during the heat treatment using (100\% to $95 \%) \mathrm{GC}$ with amorphous cellulose ( $0 \%$ to $5 \%$ ) as well as using the combination of (100\% to $85 \%$ ) GC with ( $0 \%$ to $15 \%$ ) MCC (data not shown). In addition, intensive forming was found at $2 \%$ to $4 \%$ wood powder and GC acid $98 \%$ to $96 \%, 2 \%$ TMP, and GC $98 \%$ of materials during heat treatment (Fig. 5), with wood powder at $10 \%$ of DW basis with $90 \%$ GC (Fig. $3 \mathrm{c}$ ). The foaming might be a problem in many applications, but might also be valuable in applications such as isolating materials and applications where stiff material with low density is required.
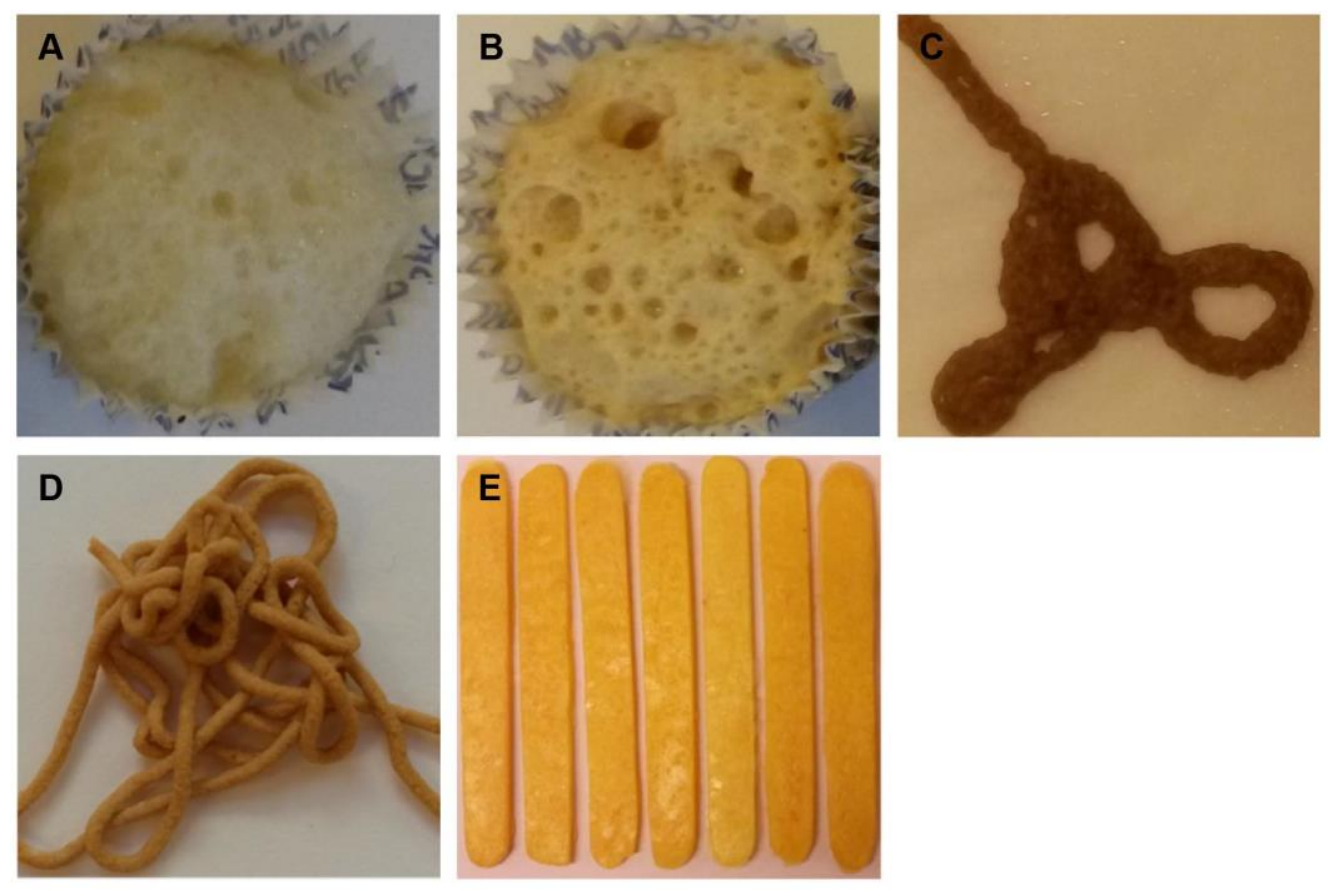

Fig. 3. Foaming materials. (A) Microwave cured citric acid/glycerol; (B) microwave cured citric acid/ethylene glycol; (C) $10 \%$ wood powder $+90 \%$ GC polymer; (D) suppression of foaming $50 \%$ mixture of ( $10 \%$ wood powder $+90 \%$ GC polymer with amorphous cellulose) during curing at 175 ${ }^{\circ} \mathrm{C}, 1 \mathrm{~h}$; (E) oven cured (10\% amorphous cellulose $+90 \%$ GC polymer) material $(80 \times 7 \times 2 \mathrm{~mm})$ $175^{\circ} \mathrm{C}, 1 \mathrm{~h}$, for tensile test.

Table 1. Strain at Break, Tensile Strength, and Elastic Modulus for Cured "Plastic Gel" Prepared from Different Combinations Plasticizer Mix and Cellulose

\begin{tabular}{|l|c|c|c|}
\hline \multicolumn{1}{|c|}{ Treatments/Mixtures } & $\begin{array}{c}\text { Strain at Break } \\
(\%)\end{array}$ & $\begin{array}{c}\text { Max. Stress } \\
(\mathrm{MPa})\end{array}$ & $\begin{array}{c}\text { Elastic Modulus } \\
(\mathrm{MPa})\end{array}$ \\
\hline MCC (unmodified) & $7 \pm 2$ & $21 \pm 3$ & $701 \pm 109$ \\
\hline MCC 20\% + GC 80\% & $7 \pm 1$ & $30 \pm 4$ & $874 \pm 51$ \\
\hline MCC 25\% + GC 75\% & $5 \pm 2$ & $11 \pm 2$ & $618 \pm 117$ \\
\hline MCC 20\% + EGC 80\% & $6 \pm 2$ & $11 \pm 1$ & $559 \pm 74$ \\
\hline MCC 25\% + EGC 75\% & $6 \pm 2$ & $19 \pm 4$ & $677 \pm 53$ \\
\hline Amor (Amorphous) & $14 \pm 5$ & $37 \pm 3$ & $755 \pm 121$ \\
\hline Amor 6\% + GC 94\% & $3 \pm 1$ & $7 \pm 1$ & $451 \pm 82$ \\
\hline Amor 10\% + GC 90\% & $5 \pm 3$ & $10 \pm 1$ & $485 \pm 111$ \\
\hline Amor 6\% + EGC 94\% & Amor 10\% + EGC 90\% &
\end{tabular}




\section{Mechanical Properties of the Material}

The present findings from FTIR as well as the hardening of the material after curing indicated that the cellulose was crosslinked by polymerized citric acid and glycerol/ ethylene glycol (Fig. 1 and 5). The effect of different celluloses, plasticizers, and plasticizer content on the tensile properties of the plastic gel was studied. The tensile properties of the new materials with different celluloses and plasticizer contents are shown in Table 1.

All three parameters, strain at break, tensile strength, and elastic modules, increased with GC rather than EGC of materials with both MCC and amorphous cellulose in respective compositions (Table 1). When 3D-printed structures are porous, this leads to poor mechanical properties and less loading of active materials (Fu et al. 2017). Therefore, GC is a more suitable plasticizer mix than EGC for the cellulose substrate of new biomaterial developments for 3D printers or packaging according to experiment combinations that were tested in this study. In addition, the results indicated that both strain at break and the tensile strength in the materials of modified cellulose (amorphous) was higher than MCC when using GC. The materials including amorphous cellulose and GC showed the highest strain at break (14\%) and maximum stress $(37 \mathrm{MPa})$ in comparison to all other materials (Table 1). This result shows that even though amorphous cellulose (6\% to $10 \%)$ had a lower percentage of DW contribution than MCC (20\% to $25 \%)$, it might have a higher crosslinking ability with GC because it is without crystals and amorphous in nature, which would facilitate higher tensile properties while MCC contains both an amorphous and crystal nature, which might be restricting crosslinking ability with GC. The tensile strength was increased by $150 \%$ in the case of crosslinked starch films with citric acid (Reddy and Yang 2010). However, strain at break and maximum stress in the materials of EGC with MCC was considerably higher than when using amorphous cellulose (Table 1). Thus, the crosslinking ability of this system probably can function with either amorphous or highly-crystalline cellulose, although more bonds are probably formed by amorphous cellulose. Thus, mixtures of amorphous and crystalline cellulose might be interesting. However, the poor mechanical properties often lead to structure failure, making 3D-printed structures vulnerable for handling (Fu et al. 2017). Therefore, the optimal material combinations were either $10 \%$ amorphous cellulose and $90 \%$ GC or $25 \%$ MCC and $75 \% \mathrm{GC}$ for 3D printing application.

\section{FTIR (Fourier Transform Infrared Spectroscopy) Analysis}

In order to confirm the formation of structure and crosslinked nature of plastic gel during curing, the FTIR analysis spectra of the plastic gel made of $(25 \% \mathrm{MCC}+75 \% \mathrm{GC}$ and $25 \% \mathrm{MCC}+75 \%$ EGC) before curing and cured $\left(175^{\circ} \mathrm{C}\right)$ were conducted (Fig 4). During heating/curing, the broad band at approximately $3400 \mathrm{~cm}^{-1}$ in both plastic gel chips $(\mathrm{MCC}+\mathrm{GC}$ and $\mathrm{MCC}+\mathrm{EGC})$, corresponding to $\mathrm{C}-\mathrm{OH}$ was shown to become much smaller after curing (Figs $4 \mathrm{~b}$ and $4 \mathrm{~d}$ ) than before curing (Figs $4 \mathrm{a}$ and 4c), respectively. This indicates a partial conversion of the available hydroxyl groups and formation of ester bonds (Pramanick and Ray 1988; Holser 2008). Also, the band size at approximately $3400 \mathrm{~cm}^{-1}$ for the MCC and GC chips cured at $175^{\circ} \mathrm{C}$ was shown much smaller than similar samples made from MCC and EGC (Fig 4b and 4d). It indicates a degree of esterification and crosslinking that related to mechanical properties of the material. As shown in Table 1, maximum stress of $(25 \% \mathrm{MCC}+75 \% \mathrm{GC})$ was significantly higher $(30 \mathrm{MPa})$ while $(25 \%$ $\mathrm{MCC}+75 \% \mathrm{EGC}$ ) was $11 \mathrm{MPa}$.

Kudahettige-Nilsson et al. (2018). "Glycerol/citric," BioResources 13(3), 6600-6612. 
A
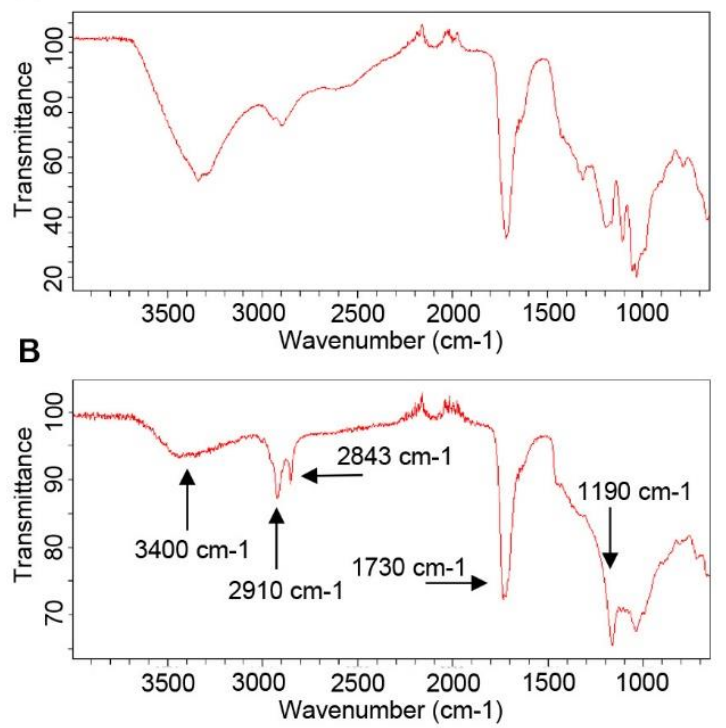

C
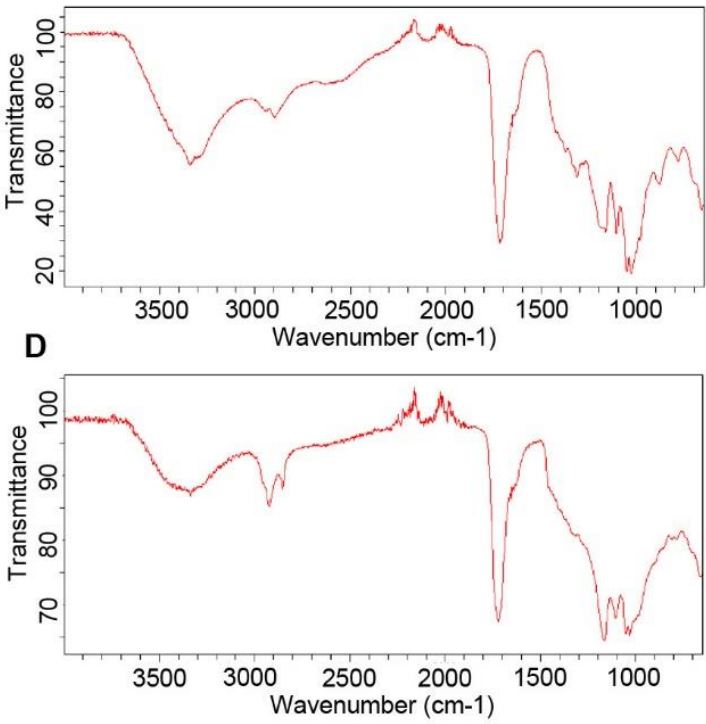

Fig. 4. FTIR spectra of the plastic gel chips made of $25 \% \mathrm{MCC}+75 \% \mathrm{CG}$ (A) before curing; (B) after curing; $25 \% \mathrm{MCC}+75 \% \mathrm{ECG}(\mathrm{C})$ before curing; (D) after curing at $\left(175^{\circ} \mathrm{C}\right)$ during $1 \mathrm{~h}$.

The polymerization reaction rate depends on temperature. With curing at $175{ }^{\circ} \mathrm{C}$, both the MCC-GC and the MCC-EGC plastic gel chips showed increased peak intensities at $1730 \mathrm{~cm}^{-1}$ and a newly formed peak at $1190 \mathrm{~cm}^{-1}$ (Fig $4 \mathrm{~b}$ and $4 \mathrm{~d}$ ). This indicates that curing treatment enhanced the intense stretching absorbance for the ester $\mathrm{C}=\mathrm{O}$ and newly created C-O stretching absorbance, respectively (Pramanick and Ray 1988). Moreover, very intense peaks at $2910 \mathrm{~cm}^{-1}\left(\mathrm{CH}_{2}\right.$ asymmetric stretching $)$ and $2843 \mathrm{~cm}^{-1}\left(\mathrm{CH}_{2}\right.$ symmetric stretching) (Altunas et al. 2017) were apparent for both MCC-GC and MCCEGC, plastic gel chips after curing at $175^{\circ} \mathrm{C}$ (Fig $4 \mathrm{~b}$ and $\left.4 \mathrm{~d}\right)$. This indicates the presence of the glycerol and ethylene glycol respectively, in the structure of the new plastic composites. From these results, which further explains nature and possibility of polymerization and crosslinking of cellulose with two-plasticizer mix GC and EGC, it appears, as the polymerization is temperature dependent and driven.

\section{Water Stability of the Material}

The material was insoluble to water initially (Table 2). According to Pramanick and Ray (1988), synthesized citric acid glycerol polymers were initially insoluble in water and in common organic solvents. In this study, polymeric materials of cellulose crosslinked plasticizers were also initially insoluble in water. However, WA analysis demonstrated that all materials absorbed increasing amounts of water over time (Table 2). Water immersion times of 1, 2, 3, 4, 6, and $24 \mathrm{~h}$ were studied, and results indicated that the water absorption vales increased with time for all the materials (Table 2). This was in agreement with Avci et al. (2017), who observed that water absorption of new biocomposites from black pine bark and oak bark were increased from $10 \%$ to $50 \%$ with immersion time $24 \mathrm{~h}$ to $72 \mathrm{~h}$. The results of WA of materials of cellulose (MCC and modified) with GC was significantly higher than materials of cellulose (MCC and modified) with EGC, $24 \mathrm{~h}$ after water immersion (Table 2). A significant difference was indicated of WA for material modified (amorphous) cellulose with GC (30\% to 40\%) and EGC (12\% to 20\%) after $24 \mathrm{~h}$ of water absorption (Table 2). In addition, a preferable difference was indicated of WA for material 
modified (MCC) cellulose with GC (28\% to 35\%) and EGC (22\% to $27 \%)$ after $24 \mathrm{~h}$ of water absorption (Table 2).

Table 2. Water Absorption (WA) and Ash Content of Plastic Gel Made by Using Different Composition of Amorphous Cellulose (6 \& 10\%) and MCC (20 \& 25\%) using Both Plasticizer Mixtures

\begin{tabular}{|c|c|c|c|c|c|c|c|c|}
\hline \multicolumn{8}{|c|}{ WA (\%) } & Ash (\%) \\
\hline Treatments/Mixtures & $\begin{array}{c}0 \\
\text { Hour }\end{array}$ & $\begin{array}{c}1 \\
\text { Hour }\end{array}$ & $\begin{array}{c}2 \\
\text { Hour }\end{array}$ & $\begin{array}{c}3 \\
\text { Hour }\end{array}$ & $\begin{array}{c}4 \\
\text { Hour }\end{array}$ & $\begin{array}{c}6 \\
\text { Hour }\end{array}$ & $\begin{array}{c}24 \\
\text { Hour }\end{array}$ & \\
\hline \multicolumn{8}{|l|}{ MCC (Unmodified) } & \\
\hline MCC $20 \%+$ GC $80 \%$ & 0 & 3 & 5 & 6 & 10 & 17 & 28 & 0 \\
\hline MCC $25 \%+$ GC $75 \%$ & 0 & 2 & 3 & 4 & 6 & 8 & 35 & 0 \\
\hline MCC $20 \%+$ EGC $80 \%$ & 0 & 6 & 8 & 10 & 12 & 15 & 22 & 0 \\
\hline MCC 25\% + EGC 75\% & 0 & 18 & 18 & 19 & 21 & 23 & 27 & 0 \\
\hline \multicolumn{8}{|l|}{ Amor (Amorphous) } & \\
\hline Amor $6 \%+$ GC $94 \%$ & 0 & 2 & 4 & 5 & 7 & 11 & 40 & 0 \\
\hline Amor $10 \%+$ GC $90 \%$ & 0 & 2 & 2 & 3 & 3 & 5 & 30 & 0 \\
\hline Amor $6 \%+$ EGC $94 \%$ & 0 & 5 & 8 & 9 & 11 & 12 & 13 & 0 \\
\hline Amor $10 \%+$ EGC $90 \%$ & 0 & 4 & 5 & 6 & 7 & 8 & 20 & 0 \\
\hline
\end{tabular}

The initial WA ability of the materials of both (amorphous and MCC) cellulose with GC were lower than EGC (Table 2) during 1 to $6 \mathrm{~h}$. This suggests that the degree of hydrolysis ability of crosslinking of cellulose plasticizer mixtures and gradual uptake of water might facilitate biodegradability of the material. According to the literature, the initially insoluble polymers of citric acid/glycerol became soluble within 8 to 10 days after being suspended in water, probably due to partial hydrolysis of the cross-links (Pramanick and Ray 1988). Even though these new materials were affected by water after long exposure, it has interesting plasticity and flexibility for 3D printing application or packing. In addition, slow uptake of water of new material might be acceptable for indoor applications. Different surface modifying treatments, such as coating, could be used to facilitate more water resistance. The relative resistance to humidity of the present material compared with pure glycerol/citric acid polymer is probably due to cellulose being covalently attached to the glycerol/ethylene glycol and glycerol/citric acid polyester.

\section{Ash Content of the Material}

Ash content is the most important characteristic of cellulose intended to be manufactured for electrically insulating materials, and the presence of ash increases dielectric loses of materials (Torgovnikov 1999). Low ash content is also an advantage for consumption material, such as packaging, etc., that eventually will be burned as waste. In addition, the nature of the mineral components and their composition are also important. In this study, the materials have been prepared based on cellulose and polyols, and citric acid mixes, via catalyst-free esterification. Ash content (fresh weight basis) of the new materials was analyzed and results indicated that all the combinations of materials were without any ash content (Table 2). Therefore, these new materials can be used for electrical insulating products and ecofriendly packaging products for electrical equipment, as the polymer is probably biodegradable and ash free. 


\section{Technical Significance}

It was possible to make plastic materials from $100 \%$ renewable resources (cellulose, thermomechanical pulp, glycerol/ethylene glycol, and citric acid), with acceptable mechanical properties, and with low ash content. The material can be interesting for a wide range of products, such as packaging materials and as medium for 3D-printers. Problems that remain to be solved include that tolerance for humidity, which might need to be improved for some applications. This study tried GC with lignocelluloses as spruce wood powder and TMP in addition to cellulose (Figs. 3c, 3d, and 5) to achieve economically feasible materials; hence, forest residues are more abundant. Interestingly, very good hard materials were produced above $15 \%$ to $20 \%$ of DW with an $85 \%$ to $80 \%$ GC mix (Fig. 5) without foaming. However, this wood powder (10\%) oriented material had very good viscosity through $(2 \mathrm{~mL})$ syringe pressing at $40{ }^{\circ} \mathrm{C}$ and did not show any deformation at $40{ }^{\circ} \mathrm{C}$, with favorable mimicking of 3D printers inlet at the lab scale. However, after curing that material at $175{ }^{\circ} \mathrm{C}$ for $1 \mathrm{~h}$, foaming triggered the deformation of the material shape (Fig. 3c).

\section{Wood powder}
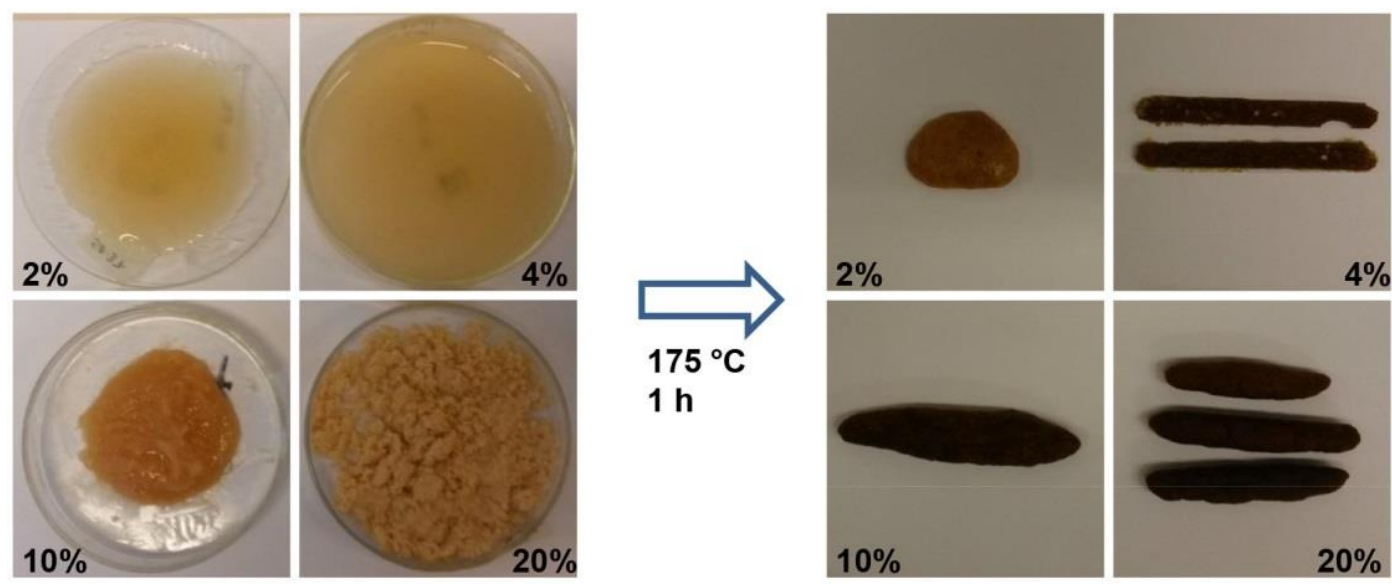

\section{TMP}
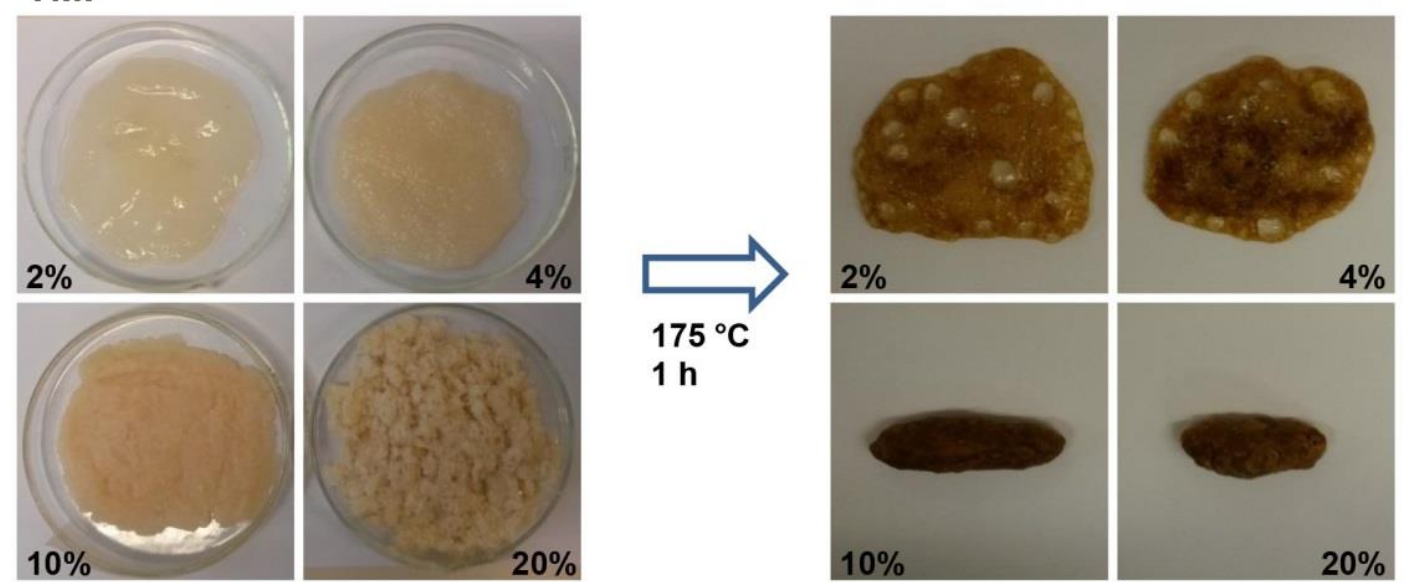

Fig. 5. Application of glycerol/citric acid with different lignocellulosic substrates. Wood powder and TMP were mixed with different compositions (2, 4, 10, and $20 \%$ DW basis) with glycerol/citric acid compositions $\left(98,96,90\right.$, and $80 \% \mathrm{DW}$ basis) respectively, cured at oven $175^{\circ} \mathrm{C}$ during $1 \mathrm{~h}$. 
Even though significant global efforts in recent years have led to the production of large quantities of biomaterials in pilot and demonstration plants, technical challenges exist in developing feedstock formulations with wood fibers, cellulosic biomaterials, or lignin with the most appropriate 3D technology ( $\mathrm{Li}$ et al. 2016). Therefore, to suppress foaming, materials with higher plasticizer content were needed. This study succeeded in suppressing the foaming during the heat treatment of materials with higher plasticizer content by adding amorphous cellulose (Fig. 3d). Heat treatment of $50 \%$ of material on a DW basis $(10 \%$ wood powder and $90 \%$ GC) mixed with $50 \%$ amorphous cellulose did not show any deformation (Fig. 3d) after the respective heat treatment. Further studies revealed that the addition of amorphous cellulose could be reduced from $50 \%$ to $25 \%$ to the wood powder $(10 \%)$ oriented material without deformation during heat treatment. This amorphous cellulose might facilitate much crosslinking between plasticizers and wood powder molecules. The exact reason is unknown, but one explanation could be that more alcohol groups are available for forming esters. As explained by Reddy and Yang (2010), polycarboxylic acid crosslinking of cellulose occurs mainly through the hydroxyl groups, and starch also contains considerable amounts of hydroxyl groups and is more accessible to chemicals by crosslinking and improves its properties. The opportunities can also come from a clever usage of wood or products of wood derivatives which are an open discussion at present to develop environmentally friendly natural/bio composite materials (Pegoretti 2017).

\section{CONCLUSIONS}

1. A stable and plastic gel was formed by cellulose/pulp, citric acid, and glycerol/ ethylene glycol.

2. The material was cured to become a hard material by heating in an oven to $175{ }^{\circ} \mathrm{C}$ for $1 \mathrm{~h}$.

3. Foaming of the materials during curing was avoided by mixing the gel portion with amorphous cellulose.

4. The cured material was insoluble in water but had certain sensitivity to prolonged exposure to water. Sensitivity towards prolonged exposure to humidity is a weakness of the material, and experiments are ongoing to apply surface modification techniques to improve water tolerability of the materials.

5. The material was free of ash content and ecofriendly.

\section{ACKNOWLEDGMENTS}

The authors would like to thank Paper Province, Karlstad, Sweden, for financial support, industrial partnership, and research collaboration. We would like to acknowledge Mikael Andersén at Chemistry division in the Karlstad University for FTIR analysis support. 


\section{REFERENCES CITED}

Altuntas, E., Yilmaz, E., Salan, T., and Alma, M. H. (2017). "Biodegradation properties of wood-plastic composites containing high content of lignocellulosic filler and zink borate exposed to two different brown-rot fungi," BioResources 12(4), 7161-7177. DOI: $10.15376 /$ biores.12.4.7161-7177

Avci, E., Acar, M., Gonultas, O., and Candan, Z. (2017). "Manufacturing biocomposites using black pine bark and oak bark," BioResources 13(1), 15-26. DOI: 10.15376/biores.13.1.15-26

Fu, K., Yao, Y., Dai, J., and Hu, L. (2017). "Progress in 3D printing of carbon materials for energy-related applications," Adv. Mater. 29(9). DOI: 10.1002/adma.201603486

Garcia, M. A., Martino, M. N., and Zaritzky, N. E. (1998). "Plasticized starch-based coatings to improve strawberry (Fragariax ananassa) quality and stability," J. Agr. Food Chem. 46(9), 3758-3767. DOI: 10.1021/jf980014c

Gonzáles Seligra, P., Medina Jaramillo, C., Famá, L., and Goyanes, S. (2016).

"Biodegradable and non-retrogradable eco-films based on starch-glycerol with citric acid as crosslinking agent," Carbohyd. Polym 138, 66 - 74. DOI:

10.1016/j.carbpol.2015.11.041

Holser, R. A. (2008). "Thermal analysis of glycerol citrate/starch blends," J. Appl. Polym. Sci. 110(3), 1498-1501. DOI: 10.1002/app.27651

Javed, A., Ullsten, H., Ernstsson, M., and Järnström, L. (2016). "Study of starch and starch-PVOH blends and effects of plasticizers on mechanical and barrier properties of coated paperboard," Nord. Pulp. Pap. Res. J. 31(3), 499-510. 10.3183/NPPRJ2016-31-03-p499-510

Li, T., Aspler, J., Kingsland, A., Cormier, L. M., and Zou, X. (2016). “3d printing-A review of technologies, markets, and opportunities for the forest industry," J. Sci. Technol. For. Prod. Process 5(2), 30.

Lourdin, D., Coignard, L., Bizot, H., and Colonna, P. (1997). "Influence of equilibrium relative humidity and plasticizer concentration on the water content and glass transition of starch materials," Polymer 38(21), 5401-5406. DOI: 10.1016/S00323861(97)00082-7

Luyt, A. S. (2017). "Are biodegradable polymers the solution to the world's environmental problems?," Express Polym. Lett. 11, 764-764. DOI: 10.3144/expresspolymlett.2017.73

Mathew, A. P., and Dufresne, A. (2002). "Plasticized waxy maize starch: Effect of polyols and relative humidity on material properties," Biomacromolecules 3(5), 11011108. DOI: 10.1021/bm020065p

Menzel, C., Olsson, E., Plivelic, T. S., Andersson, R., Johansson, C., Kuktaite, R., Järnström, L., and Koch, K. (2013). "Molecular structure of citric acid cross-linked starch films," Carbohyd. Polym 96, 270 - 276. DOI: 10.1016/j.carbpol.2013.03.044

Pegoretti, A. (2017). "Expressing polymers for a sustainable development," Express Polym. Lett. 11, 852-852. DOI: 10.3144/expresspolymlett.2017.81

Pramanick, D., and Ray, T. (1988). "Synthesis and biodegradation of copolyesters from citric acid and glycerol," Polym. Bull. 19(4), 365-370. DOI: 10.1007/BF00263938

Reddy, N., and Yang, Y. (2010). "Citric acid cross-linking of starch films," Food Chem. 118(3), 702-711. DOI: 10.1016/j.foodchem.2009.05.050

Shi, R., Zhang, Z., Liu, Q., Han, Y., Zhang, L., Chen, D., and Tian, W. (2007). "Characterization of citric acid/glycerol co-plasticized thermoplastic starch prepared 
by melt blending," Carbohyd. Polym. 69(4), 748-755. DOI:

10.1016/j.carbpol.2007.02.010

Tham, W. H., Wahit, M. U., Kadir, M. R. A., Wong, T. W., and Hassan, O. (2016).

"Polyol-based biodegradable polyesters: A short review," Rev. Chem. Eng. 32(2), 201-221. DOI: 10.1515/revce-2015-0035

Tisserat, B., O'kuru, R. H., Hwang, H., Mohamed, A. A., and Holser, R. (2012).

"Glycerol citrate polyesters produced through heating without catalysis," J. Appl. Polym. Sci. 125(5), 3429-3437. DOI: 10.1002/app.36669

Torgovnikov, G. I. (1999). Dielectric Properties of Wood and Wood-based Materials, Springer, Berlin, Germany.

Wang, R., Zhang, J., Kang, H., and Zhang, L. (2016). "Design, preparation and properties of bio-based elastomer composites aiming at engineering applications," Key. Eng. Mater. 133, 136-156. DOI: 10.1016/j.compscitech.2016.07.019

Wang, Y., Lindström, M. E., and Henriksson, G. (2014). "Increased degradability of cellulose by dissolution in cold alkali," BioResources 9(4), 7566-7578. DOI: 10.15376/biores.9.4.7566-7578

Wu, D., Qian, X., and Shen, J. (2017). "Macromolecular reorganization as a basis for converting cellulosic hydrogels into sustainable plastics," BioResources 12(4), 69026903. DOI: 10.15376/biores.12.4.6902-6903

Yang, C. Q., Wang, X., and Kan I-S. (1997). "Ester crosslinking of cotton fabric by polymeric carboxylic acids and citric acid," Textile Res. J. 67 (5), 334 - 342. DOI: 10.1177/004051759706700505

Yang, J., Webb, A. R., and Ameer, G. A. (2004). "Novel citric acid-based biodegradable elastomers for tissue engineering," Adv. Mater. 16(6), 511-516. DOI:

10.1002/adma.200306264

Article submitted: March 22, 2018; Peer review completed: May 31, 2018; Revised version received: June 27, 2018; Accepted: July 5, 2018; Published: July 13, 2018. DOI: 10.15376/biores.13.3. 6600-6612 